\title{
Contemporary Applied Business Research in Light of Academic Literature
}

\author{
Special Issue \\ International Journal of Applied Research \\ in Business and Management
}

Greetings From the Publisher

Atilla Wohllebe

aw@wr-publishing.org

Wohllebe \& Ross Publishing,

Hamburg, Germany

\author{
Florian Ross \\ fr@wr-publishing.org \\ Wohllebe \& Ross Publishing, \\ Hamburg, Germany
}

Dear Reader,

Dear Authors,

Dear Editorial Board Members,

every year young and also experienced scientists worldwide write hundreds of thousands, maybe millions of essays and literature reviews. Some of them are probably not read more than once and are lost knowledge afterwards.

With this special issue of the International Journal of Applied Research in Business and Management, we would like to provide a platform for these papers. Therefore, we have called for short scientific essays and literature reviews that bridge the gap between academic literature and practiceoriented research. The result is the following very different papers, which we are proud to present as a special issue of the journal.

We would like to take this opportunity to thank not only the authors of this issue, but also all the other people who support the journal through their contributions - as authors, as editors, and also as interested readers. When we launched the International Journal of Applied Research in Business Management, the first academic journal published by Wohllebe \& Ross Publishing, about two years ago, we did not expect this great response.

We look forward to the further development of the journal and many more issues to come!

Atilla Wohllebe and Florian Ross

Managing Partners

Wohllebe \& Ross Publishing

Hamburg, Germany, 2022 